\title{
Article
}

\section{Developing Epistemological Understanding in Scientific and Social Domains through Argumentation}

\author{
Iordanou, Kalypso
}

Available at http://clok.uclan.ac.uk/23899/

Iordanou, Kalypso ORCID: 0000-0001-5930-9393 (2016) Developing

Epistemological Understanding in Scientific and Social Domains through

Argumentation. Zeitschrift für Pädagogische Psychologie, 30 (2-3). pp. 109-

119. ISSN 1664-2910

It is advisable to refer to the publisher's version if you intend to cite from the work.

http://dx.doi.org/10.1024/1010-0652/a000172

For more information about UCLan's research in this area go to http://www.uclan.ac.uk/researchgroups/ and search for <name of research Group>.

For information about Research generally at UCLan please go to http://www.uclan.ac.uk/research/

All outputs in CLoK are protected by Intellectual Property Rights law, including Copyright law. Copyright, IPR and Moral Rights for the works on this site are retained by the individual authors and/or other copyright owners. Terms and conditions for use of this material are defined in the policies page.

\section{CLoK}

Central Lancashire online Knowledge www.clok.uclan.ac.uk

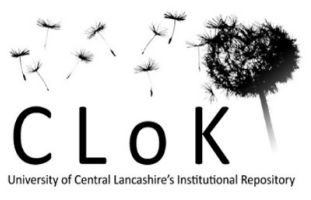


Developing Epistemological Understanding in Scientific and Social Domains through Argumentation

Kalypso Iordanou*

University of Central Lancashire Cyprus

*Contact: KIordanou@uclan.ac.uk

12-14 University Avenue, Pyla, Larnaca, 7080, Cyprus 


\title{
Developing Epistemological Understanding in Scientific and Social Domains through Argumentation
}

\begin{abstract}
The present work examines whether engagement in an argument-based intervention can support the development of evaluativist epistemological understanding. Students were randomly assigned to one of two intervention conditions - focusing on either a social or science topic - and their epistemological understanding was assessed before and after the intervention using both a social and a science topic. Students' views about their own and scientists' processes of knowing were also assessed. Results showed that engagement in dialogic argumentive activities supported the development of more evaluativist domain-specific epistemological understanding. Further qualitative analysis showed domain differences in how participants valued evidence in the process of knowing, supporting the view that there are different challenges in the development of epistemological understanding across domains. Overall, the present study's findings have important educational implications and suggest that engagement in argumentive activities is a promising pathway for supporting the development of epistemological understanding.
\end{abstract}


Epistemological beliefs are individuals' beliefs about knowledge and knowing (Hofer \& Pintrich, 1997). Within the epistemological beliefs literature, there are two main theoretical frameworks: the multidimensional approach and the developmental approach. The multidimensional approach conceptualizes epistemological beliefs as a system of more or less independent beliefs (Hofer, 2004; Schommer, 1994), whereas the developmental approach proposes that there is a developmental progression of epistemological understanding (Kitchener \& King, 1994; Kuhn, 1991; Perry, 1970). Despite this difference, the actual dimensions of beliefs proposed by each approach are relatively consistent (Hofer, 2004); further, the two approaches similarly conceptualize beliefs on a continuum from less constructivist to more constructivist (e.g., that knowledge is personally constructed). Moreover, although several multidimensional frameworks have been proposed, these too share commonalities that can be categorized along four dimensions (Hofer \& Pintrich, 1997). Two of these dimensions, (1) the certainty of knowledge, which ranges from absolute to tentative knowledge, and (2) simplicity of knowledge, which ranges from viewing knowledge as the sum of simple facts to viewing knowledge as a complex net of interrelated concepts, refer to the nature of knowledge. The other two dimensions, (3) source for knowing, which ranges from the belief that knowledge is transmitted from external authority to the belief that knowledge is constructed by individuals, and (4) justification for knowing, which ranges from the belief that direct observation of the world and authority are the sources of knowing to the belief that knowledge is acquired through the application of the rules of inquiry and evaluation, refer to the nature of knowing.

The present study focuses on the development of epistemological understanding and, thus, the developmental approach to epistemological understanding has been used. According to this approach, the developmental task that underlies the progression toward mature 
epistemological understanding is the coordination of the subjective and objective components of knowing (Greene et al., 2008; Hofer, 2004; Kuhn, Cheney, \& Weinstock, 2000). In this context, epistemological understanding progresses from the absolutist level to the multiplist level and, finally, to the evaluativist level (Kuhn et al., 2000). In the absolutist level, the objective dimension of knowing dominates. Knowledge is conceived as an objective, external entity, which is knowable with certainty. In the mutliplist level, there is a radical transition from an objective view of knowledge to the subjective view of knowledge. Knowledge is no longer considered an object that is located in the external world, but a product of the human mind which is located in one's self. At the multiplist level, the uncertain and subjective nature of knowledge comes to the foreground and dominates one's view of knowledge. The realization that knowledge is constructed by human minds drives multiplists to the conclusion that knowledge is entirely subjective. To the multiplist, evaluating beliefs is both pointless and impossible, since there are no objective standards that could serve as the basis for evaluation of conflicting claims. At the evaluativist level, a balance is achieved between the objective and subjective components of knowledge (Kuhn et al., 2000). Knowledge at this level is neither conceived as an objective entity available in the external world waiting to be discovered, nor as a totally relativistic, subjective opinion. Mature epistemological understanding instead involves the coordination of the subjective and objective components of knowledge. If knowledge evolves through coordination of theory with data, then evaluation plays a central role in mature epistemological understanding. Through evaluation, the position found to be best supported by argument and evidence would be determined to have more merit compared to alternative positions (Kuhn et al., 2000).

The development of epistemological understanding is both domain general and domain specific. The developmental pattern of progression of epistemological understanding, ranging 
from absolutist to evaluativist epistemological understanding, is common across domains (Kuhn et al., 2000); however, several studies have documented that an individual's epistemological understanding can differ across domains and topics (Kuhn et al., 2000; Kuhn, Iordanou, Pease \& Wirkala, 2008). The work of Kuhn, Iordanou et al. (2008) suggests that there are qualitatively different challenges in the development of epistemological understanding across domains. Specifically, the major challenge in the social domain is to overcome the view that human interpretation plays an unmanageable, overpowering role, whereas the major challenge in the science domain is to recognize that human interpretation plays any role at all.

Epistemological beliefs are fundamental for learning and thinking. Researchers, in an effort to gain an understanding of how individuals' beliefs about knowledge and knowing relate to their learning and reasoning, examined the influence of epistemological understanding on problem solving in the context of mathematics problem solving (Muis, 2008), educational psychology (Muis \& Franco, 2010), conceptual change in the context of physics (Mason et al., 2008; Nussbaum, Sinatra, \& Poliquin, 2008), text comprehension (Schommer et al., 1992; Støms $\varnothing$, Bråten, \& Britt, 2011), internet-based learning (Mason, Ariasi, \& Boldrin, 2011; Mason, Boldrin, \& Ariasi, 2010; Strøms \& \& Bråten 2010) and reasoning (Mason \& Scirica, 2006). This line of research showed an association between constructivist beliefs about knowledge and knowing and the development of advanced thinking skills and learning (Hofer \& Pintrich, 1997; Mason, Ariasi \& Boldrin, 2011). For example, Mason et al. (2010) found that students who viewed comparison of multiple sources and scientific evidence as an appealing means to justify knowledge had higher gains from online learning. In an effort to understand how epistemological beliefs support thinking and learning, Iordanou et al. (submitted) used a think-aloud methodology to examine relations between individuals' epistemological understanding and online processing 
of evidence while reading text. Their findings showed that participants who exhibited evaluativist epistemological understanding engaged in more meta-level processing of evidence; that is, they reflected more on the evidence's credibility and its function in the context of argument, compared to participants who held non-evaluativist epistemological understanding. Given the importance of epistemological understanding to learning and thinking, research findings showing that most children and even adults hold non-constructivist views of knowledge (Kuhn et al., 2000; Leach, Driver, Millar, \& Scott, 1997) are a source of concern. Thus, the question of how to support the development of epistemological understanding is a central one.

In the present study I propose that engagement in dialogic argumentation can be a promising condition for supporting the development of epistemological understanding. The context of dialogic argumentation involves exposure to alternative positions, a need to justify one's own position with evidence to an opponent, and a need to challenge the opponent's position — conditions which may facilitate the development of an evaluativist epistemological understanding. Exposure to alternative positions supported by evidence could prompt individuals to abandon absolutist epistemological views of a single objective reality. Also, receiving and providing criticism could help individuals to develop an appreciation of the role of argument and evidence in knowledge construction. Some studies that examined the epistemic dimensions of argumentation (that is, students' epistemological understanding of what constitutes an acceptable claim to knowledge during argumentation), found that when students engaged in extensive practice in dialogic argumentation, their understanding and application of epistemic criteria, such as the explicit justification of claims with appropriate evidence, improves (Iordanou \& Constantinou, 2014; 2015; Kuhn, Zillmer, Crowell, \& Zavala, 2013). When 11th graders engaged in collaborative dialogic argumentation within the SOCRATES web-based learning environment, 
Iordanou and Constantinou (2015) observed an increase in students' use of scientific data to support their arguments, an increase in citations of their data sources, and a decrease in employment of personal opinions. These findings suggest that students developed, at least implicitly, an epistemological understanding of the constructive nature of scientific knowledge. Students exhibited a shift from presenting their "right," unsupported self-evident theories of how things are, to employing data to support their positions and offering alternative interpretations for particular pieces of evidence. Observing students engaged in prolonged dialogic argumentation, Kuhn et al. (2013) reported gains in epistemological understanding of argument norms specifically in terms of what constitutes acceptable claims to knowledge and acceptable ways to advance them in discourse. Although the studies described above (Iordanou \& Constantinou, 2015; Kuhn et al., 2013) reported improvements in students' understanding of the epistemic norms of argumentation, no direct measures for assessing students' epistemological understanding were employed.

\section{Present study}

The present work examines whether engagement in an argument-based intervention supports the development of students' epistemological understanding. The intervention involved argumentive activities, where students worked with a partner in arguing with a succession of pairs of classmates who held an opposing view on the topic, reflective activities based on transcriptions of the dialogues, and a goal-based component for maintaining students' interest and involvement throughout the intervention. Previous work showed that engagement in this intervention supported the development of students' argumentation skills (Iordanou, 2010; Iordanou \& Constantinou, 2014; 2015; Kuhn et al., 2013; Kuhn, Goh, Iordanou, \& Shaenfield, 2008). The present work extends these prior studies by examining whether engagement in an 
argument-based intervention facilitates the development of epistemological understanding. In addition, the present work examines the issue of domain-specificity of epistemological understanding. Students were randomly assigned to one of two intervention conditions - focusing on either a social topic or a science topic - and their epistemological understanding was assessed before and after the intervention in both the social and science domains, using scenario-based, domain-specific instruments. In addition, to gain a better understanding of participants’ epistemological understanding, individual interviews were conducted to examine participants' epistemological understanding about themselves and scientists within their intervention domain. We hypothesized that engagement in an argument-based intervention in a particular domain would facilitate the development of an evaluativist epistemological understanding in that particular domain, reflected in both the scenario-based instruments and individual interviews about their and scientists' process of knowledge. Given the evidence for domain specificity in epistemological understanding, we expected that this improvement in epistemological understanding would be domain specific and that students' epistemological understanding would vary across domains (Kuhn, Iordanou et al., 2008; Muis, Bendixen, \& Haerle 2006).

\section{Method}

\section{Participants}

Participants were 44 sixth graders from a public elementary school in a middle-class suburban area in the country of Cyprus. The sample consisted of the entire sixth grade of a particular school. All were 11 or 12 years of age; 27 were boys and 17 were girls. Participants were primarily from a middle-class population. Roughly $30 \%$ were from minority ethnic groups. Four participants, whose language abilities were judged by the school system as needing remediation, participated but were not included in the analysis. 


\section{Initial and Final Assessment}

Participants' epistemological understanding was assessed through (a) individual interviews based on a physical science scenario and a social science scenario - the Frog problem and the Livia problem - conducted before and after the intervention, and, (b) individual interviews about their own and scientists' epistemological understanding, conducted after the intervention. Participants' responses were audio recorded and then transcribed for analysis.

The Livia and Frog problems. To assess participants' epistemological understanding in the social and science domains, the Livia problem (Kuhn, Iordanou et al., 2008, see Table 1) and Frog problem (Linn, Shear, Bell \& Slotta, 1999, see Table 2) were used, respectively. The Livia problem presented two contradictory accounts from two historians regarding the fictitious Fifth Livia war. The Frog problem presented two contradictory accounts from two scientists about deformities observed in frogs. The two accounts for each problem were presented in a counterbalanced order. During an individual interview, which lasted about 40 minutes, participants received a hard copy of each instrument and were instructed to read the two accounts carefully and get ready to answer some questions about the accounts. Participants completed the two instruments in a counter-balanced order. Participants in each case were asked first to describe in their own words what the $5^{\text {th }}$ Livia war/frog issue was about and whether the two historians'/scientists' accounts were different in any important ways. Then participants were asked questions about the rightness of the two accounts (Could both of the historians' accounts be right? Is one of the historian's accounts more true than the other?) and the certainty of knowledge (How could you be certain of what happened in the $5^{\text {th }}$ Livia war?). 
Interviews about own and scientists' epistemological understanding. Participants' views about their own and scientists' process of knowing were examined on a separate individual interview, which took place at the final assessment. To examine participants' views about scientists' process of knowing in the science and social domains, students were asked two questions ("How do those studying the topic of dinosaurs know that dinosaurs disappeared because of the asteroid/volcanoes?"; and "How do those studying the topic of homeschooling know that children could be taught at home/should go to school?"). To examine participants' views about their own process of knowing in the science and social domains, students were asked two additional questions ("How do you know that dinosaurs disappeared because of the asteroid/ volcanoes?"; and "How do you know that children could be taught at home/should go to school?"). Finally, participants were asked to compare the way they know about the issue with the way scientists do.

\section{Table 1}

Table 2

\section{Intervention}

Each participant was randomly assigned to one of two conditions: a) the social condition or b) the science condition. The two intervention conditions were identical in terms of the activities employed except for the intervention topic: homeschooling was used for the social condition and dinosaur extinction for the science condition. The intervention took place during thirteen $40-$ minute sessions occurring twice per week in the participants' classroom. The two intervention conditions took place simultaneously, with participants taking part in only one of the two. Participants were told that they were preparing for a final "showdown" in which they would 
debate their topic (either homeschooling or dinosaur extinction) with their classmates who held the opposing view (for more details regarding the intervention see Iordanou, 2010).

Assessing Initial Positions. Participants' initial positions and supporting arguments regarding both the social topic - home-school - and the science topic - dinosaur extinction - were assessed individually in writing. For the home-school topic, participants were presented with a scenario about a Japanese child who moved to Cyprus for one year. Participants were to decide whether the child should go to the town school or whether he could be taught at home. For the dinosaur extinction topic, students were presented two scientists' views about dinosaur extinction: one scientist maintained that dinosaurs were quickly exterminated by the collision of an asteroid with Earth, while the other scientist maintained that dinosaurs disappeared gradually due to giant volcanic eruptions. Students had to decide which of the two theories should be included in the sixth graders' science book to explain dinosaur extinction. For each scenario, students could also choose the option "undecided." Based on participants' responses on the topics, two groups of 10 participants each were formed in each condition. The participants who indicated they were undecided gave reasons for both sides of the issue and were assigned to one or the other position in a way that served to equate the number of participants on each side. In the social condition, one group of students supported the homeschool option and the other group the town school option. In the science condition, one group supported the view that an asteroid collision caused the dinosaurs' extinction, where the other group supported the view that volcanic eruptions were the cause. 
Preparation for supporting reasons with evidence. Participants in each condition initially worked in groups with other same side peers. They were given a list of "some possibly relevant facts" supporting both positions of the topic in a random order. They were asked to review this information individually and then to decide as a team if there were any facts they wished to use. An adult coach, who was a researcher, facilitated each group's work, answering questions and helping to keep students focused on the task but offering no direct instruction or feedback.

Engagement in dialogic argumentation. Within each group, participants were organized into same-gender pairs. Participants were asked to collaborate with their partners and agree on what to say before typing and sending it to their opponent via instant messaging (IM). These pairs worked together on the IM dialogues until the "showdown" segment of the intervention. Participants were instructed that their goal was to convince the other pair that their position was better. They engaged in dialogic argumentation for five sessions, discussing with a different pair on each session. Two or three adult coaches (who were the same in both conditions), circulated throughout the room during these sessions, answering any questions and reminding pairs to collaborate with one another in deciding on a response.

Engagement in reflective activities. After three of the five dialogue sessions were complete, the students engaged in the first reflective activity. During these reflective sessions, a printed transcript of the preceding session's dialogue was given to participants along with a scaffold sheet. The scaffold sheets prompted students to reflect on the opposing pair's argument and their own counterargument as well as on the opponents' counterargument and their own rebuttal to the counterargument. Participants were asked to think of how they could improve 
on their counterargument or rebuttal. Adult coaches circulated to provide clarifications when necessary. A total of three reflective sessions took place, that alternated with the $3^{\text {rd }}, 4^{\text {th }}$ and $5^{\text {th }}$ dialogue sessions.

Preparation for showdown and final showdown. Participants were told to prepare for a final showdown debate with the opposing side. Participants had one session to prepare and the following session to conduct the showdown. During preparation, the participants' task was to prepare effective counterarguments to use when faced with opponents' arguments and effective rebuttals to use when faced with opponents' counterarguments in the showdown. Transcripts of the dialogues, scaffold sheets, and blank index cards were provided to participants.

Judgment and feedback. The electronic dialogue produced in the showdown was represented in an argument map prepared by the researchers. Different columns appeared for each team, with their contributions arranged in order of occurrence from top to bottom. All statements were represented and connected by lines to show their interrelation. Different colors were used to label statements as constituting effective, ineffective, or neutral argumentative moves. A point system was also applied, making it possible to declare a winning team. The argument map and associated point scoring were presented to participants in a session following the showdown.

\section{Coding}

Participants' verbal protocols were transcribed and coded by two coders. Two trained research assistants, blind to the treatment, time, and identity of the participants coded all students' responses over a semester. Disagreements between coders were resolved through discussion. 
Inter-rater reliability calculated with Cohen's kappa was 0.8 , indicating good inter-rater reliability.

The Livia and Frog problems. Responses to all three questions - regarding whether both of the historians' accounts could be right, whether one scientist can be more right than the other, and what would help us become more certain of what happened/what is the cause of the problem — were used to identify each participant's epistemic profile, based on the coding scheme developed by Kuhn, Iordanou et al. (2008). The first two questions received Yes/No responses while the third was open-ended. Participants were classified as absolutists if they responded that one view could be more right than the other and that certainty was empirically possible via direct observation of data, by asking a scientist, or by overcoming some practical limitations. They were classified as multiplists if they reported that one view could not be more right than the other and that certainty was not possible because of the subjective nature of human knowing. Finally, participants were classified as evaluativists if they reported that one view could be more right than the other and that certainty was not possible, but it could be approachable through investigation, analysis and interpretation of evidence (see examples in Table 3). If a participant exhibited epistemological beliefs that could be classified in two epistemological categories, the predominant category was used for categorization.

Students' views about their own and scientists' process of knowing. Participants' responses to the questions regarding their own and scientists' process of knowing were coded based on a coding scheme developed for the purposes of the present study. A portion of responses (15\%) from the sample was used as a basis for developing the coding scheme which included categories that captured the range of responses observed (see Tables 5 and 6). After 
devising the initial scheme, coders coded another $15 \%$ of responses to insure that the coding scheme was able to capture all responses.

Table 3

\section{Results}

\section{Development of Epistemological Understanding}

To examine our first research question of whether engagement in argumentive and reflective activity supports the development of students' epistemological understanding, a Chisquare test was conducted comparing the number of students who exhibited mature (that is, evaluativist) epistemological understanding at initial and final assessment on the intervention topic. Table 4 shows the number of participants who were profiled as absolutists, multiplists and evaluativists by condition, time, and topic. Overall, the number of participants who exhibited evaluativist epistemological understanding increased from initial to final assessment on the intervention topic, $X^{2}(1)=9.683, p=.002$. While only $10 \%$ (4 out of 39) of participants exhibited evaluativist epistemological understanding on the intervention topic, by the end of the intervention $41 \%$ (16 out of 39 ) did so (see Table 4$)$.

Table 4. Number of Students showing an Absolutist and Multiplist position at Initial and Final Assessment by Topic, Time and Condition.

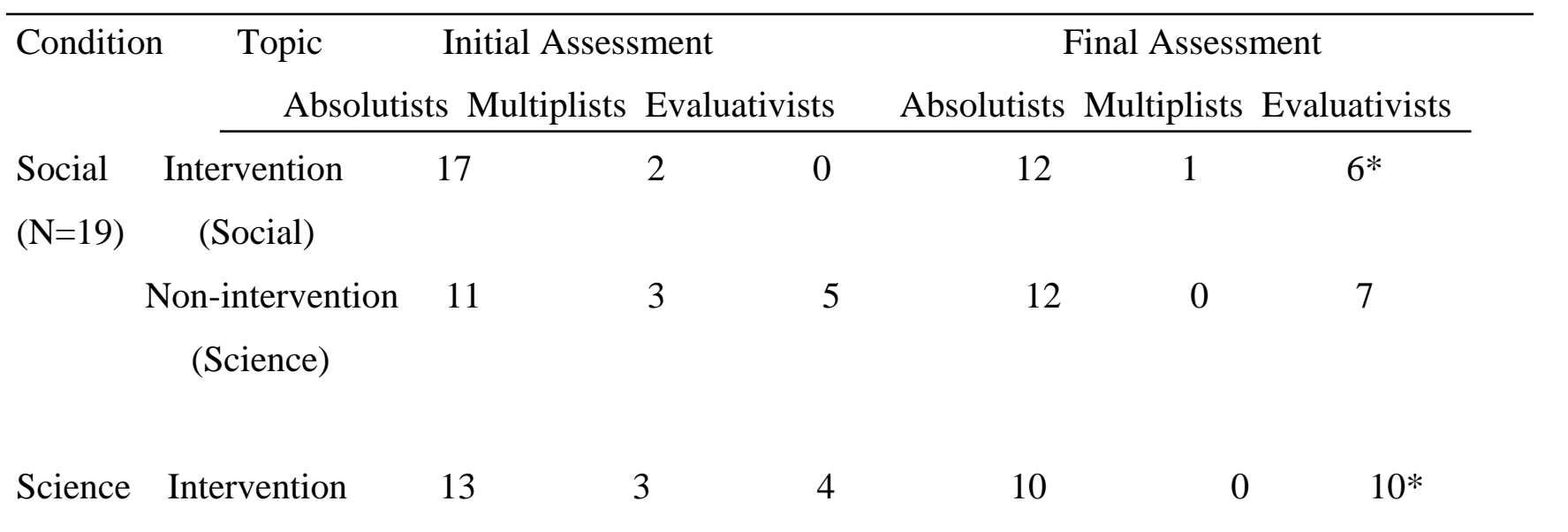


$(\mathrm{N}=20) \quad$ (Science)

Non-intervention

16

2

2

17

0

(Social)

To examine our second research question (i.e., whether development of epistemological understanding is domain specific), we ran a Chi-square test comparing improvement in epistemological understanding on the social and science topics by Condition. We coded as improvement any transition to a more mature category from initial to final assessment (that is, from absolutist to multiplist or evaluativist and from multiplist to evaluativist). Results showed that there were significant differences between participants in the social and science conditions in terms of the improvement they exhibited on the social topic, $X^{2}(1)=4.378, p=$ .036. Of participants in the social condition, six exhibited improvement in epistemological understanding while 13 did not. Of those in the science condition, only one of 20 participants improved. We observed no significant difference in improvement in epistemological understanding on the science topic between participants in the science condition and participants in the social condition, $X^{2}(1)=2.266, p=.132$. In particular, six of the science condition participants showed improvement, while 14 did not, and two of the social condition participants showed improvement, while 17 did not.

To gain a better understanding of the domain-specificity vs. domain-generality of the development of epistemological understanding, and given the small number of participants showing improvement, we also conducted a Related-Samples McNemar test comparing the number of participants who exhibited evaluativist epistemological understanding on initial and final assessments for each condition, including both intervention and non-intervention topics. 
Social Topic. At initial assessment on the social topic, none of the social condition participants and only two of the science condition participants exhibited an evaluativist epistemological understanding (see Table 4). At final assessment, there was a significant increase in the number of participants in the social condition who held an evaluativist epistemological understanding ( $p=.031$, Related-Samples, McNemar test). Six of 19 social condition participants (31.5\%) exhibited an evaluativist position at the final assessment, whereas none of them did so at initial assessment. No significant increase was observed, however, in the science condition participants.

Science Topic. On the science topic, five of 19 (or $26.3 \%$ of) social condition participants exhibited evaluativist beliefs at initial assessment, and about the same number of students, 7 out of 19 (or $36.8 \%$ ), did so at the final assessment. Whereas no significant change was observed in social condition participants on the science topic, a significant change was observed in science condition participants from initial to final assessment on the science topic. In particular, while only four of $20(20 \%)$ of science condition participants exhibited evaluativist understanding at initial assessment, half of these participants -10 of 20 - did so at final assessment $(p=.031$, Related-Samples McNemar test).

Overall, McNemar within-subjects analysis comparing participant responses at initial and final assessment on the intervention and non-intervention topics showed that the number of participants exhibiting evaluativist epistemological understanding increased from initial to final assessment on the intervention topic, but not on the transfer topic.

Students' views about Scientists' process of knowing. 
To gain further understanding regarding differences in students' epistemological understanding across domains, we examined students' responses in individual interviews about their own and scientists' process of knowing.

Social Domain. When participants in the social condition were asked how those studying the topic of homeschooling know that children could be taught at home/should go to school, 53\% - or nine of 17 (as seen in Table 5) - provided claims unsupported by evidence. For example, one student said, "Because teachers are better." Another $24 \%$ - four of 17 - claimed that scientists know because they pursue research, without giving any further details. Twelve percent - two of 17 - claimed that they know because they have first-hand observation (e.g. "because they saw it"). Six percent - one of 17 - claimed that scientists thought it, and another $6 \%$ - one of 17 - claimed that scientists know it because they have studied for many years.

Science Domain. When children in the science condition were asked how those studying the topic of dinosaurs know that dinosaurs disappeared because of the asteroid/volcanoes, $67 \%-$ 12 of 18 (as seen on Table 5) - claimed that scientists know because they found evidence. Students in this category provided pieces of evidence in their responses (e.g. mineral glass, crater in Mexico, dinosaurs' fossils and lava, or asteroid rock). Twenty-two percent - four of 18 provided undocumented evidence claims from personal knowledge. Some examples of students' responses in this category include: "there were many explosions in the past," "asteroids fall everywhere, there are no volcanoes everywhere," "there were many volcanoes," and "asteroids do not fall everyday." Eleven percent - two of 18 - claimed that scientists know because they pursue research, without giving any further details.

Social vs. Science Domain. A chi-square test comparing social- and science-condition participants' responses revealed a significant difference regarding their views of scientists' 
source of knowledge. As seen on Table 5, more science-condition students $(N=12)$ than socialcondition students $(N=1)$ identified evidence as a source of knowing for scientists $(N=1), X^{2}$ $(1)=13.836, p<.001$.

Table 5. Students' views about scientists' process of knowing in the social and science domains.

$$
\text { Science Domain }(\mathrm{N}=18) \quad \text { Social Domain }(\mathrm{N}=17)
$$

Evidence

Research

Unsupported Evidence Claims

First hand observation

Scientists' education

Thinking
$12 *$

2

4

0

0

0
1

3

9

2

1

1

$p<.001$

Students' views about their own process of knowing.

Social Domain. When students in the social condition were asked how they know that children could be taught at home/should go to school, 35\% - six of 17 - responded by providing claims from general knowledge (e.g. "you don't have friends at home"; "he will feel more comfortable to ask a question of his parents than his teachers"); $29 \%$ - five of 17 - responded by providing some personal experience (e.g., "I attend school, too, and I have friends"; "you can socialize and make friends at school; now that I'm at school I know this"); $18 \%$ - three of 17 reported that they thought this, $6 \%$ - one of 17 - claimed that they heard this from scientists; and 
$12 \%$ - two of 17 - reported that they know this because of research, without giving further details.

Science Domain. When students in the science condition were asked how they know that dinosaurs disappeared because of the asteroid/volcanoes, $67 \%$ - 12 of 17 - claimed that they knew because they had evidence, $17 \%$ - three of 17 - reported that they knew because they had read books or watched documentaries, $6 \%$ - one of 17 - claimed that they have learned from scientists, and $11 \%$ - two of 17 - reported undocumented evidence claims (e.g., an asteroid caused a tsunami).

Social vs. Science Domain. Science- and social-condition students differed in their views about their source of knowledge. In particular, more science-condition students $(N=12)$ than social-condition students $(N=0)$ reported that evidence is the source of their knowledge, $(p<$ .001 , Fisher's Exact Text).

Table 6. Students' views about their own process of knowing in the social and science domains.

$$
\text { Science Domain }(\mathrm{N}=18) \quad \text { Social Domain }(\mathrm{N}=17)
$$

Evidence

Research

Books, encyclopedia, documentaries

Scientists

Unsupported evidence claims

Thinking

\section{$12 *$}

0

3

0

2

0

1

6

3 
$* p<.001$

How students compare scientists' and their own process of knowing.

Social Domain. Nine of 17 (or $53 \%$ of) students in the social condition claimed that the way they know about the topic and the way scientists do is the same. Twenty-nine percent - five of 17 - claimed that they and scientists share the same reasons (e.g., that there are better opportunities for acquiring knowledge and making friends at school). Twelve percent - two of 17 - claimed that both they and scientists know about the issue through thinking about it, while another $12 \%$ responded that the way they know about the issue and the way scientists do is the same, but without providing any explanation. Forty-seven percent - eight of 17 - claimed that the way they have learned about the issue is different from the way scientists did. In particular, 24\% - four of 17 - reported that they know from personal experience while scientists know because they pursue research, $18 \%$ - three of 17 - claimed that scientists know better than they do, and $9 \%$ - one of 17- claimed that the way they have learned differ with the way scientists have learned, but they didn't provide any further explanation.

Science Domain. All the students in the science condition reported that scientists pursue research and find evidence, while they (the students) study the evidence that scientists produce. Some examples from students' responses include: "I learn from them, they pursue research"; "we have evidence, they pursue research"; "I learned it from books and films, scientists discovered it"; "I support this because there are more evidence, scientists find evidence."

Social vs. Science Domain. Science- and social-condition participants differed in how they compared scientists' and their own processes of knowing. While only eight of the 17 social- 
condition students claimed that there was a difference between how they had acquired knowledge about their intervention topic and how scientists did, all science-condition students claimed that the way they had learned about their intervention topic was different from the way scientists did, $p<.001$, Fisher's Exact Test.

\section{Discussion}

Results showed that engagement in dialogic argument activities supported the development of more constructivist domain-specific epistemological understanding. In particular, participants in the science condition showed a significant advance in epistemological understanding in the science domain only, whereas participants in the social condition showed a significant advance in epistemological understanding in the social domain only. These findings show that extensive engagement in an argumentative activity is a promising condition for supporting the development of epistemological understanding. Notably, in the present study there was no direct instruction of the role of evidence or evaluation for belief formation, therefore the improvements observed in participants' epistemological understanding cannot be attributed to learning from direct teaching. Also, the fact that gains in participants' epistemological understanding were observed in a non-intervention topic suggests that these improvements can be attributed to the development of an appreciation of the role of evidence and evaluation in knowledge acquisition.

Qualitative analysis of participants' responses regarding their own and scientists' epistemological understanding revealed differences between participants who engaged in an intervention focused on a social topic and those who engaged in one focused on a science topic — particularly in terms of how they valued evidence for the process of knowing. Students considered evidence to be the main source of their own and scientists' knowledge in the physical 
science domain, while personal experience and subjective thinking were considered to be the main source of knowing in the social science domain. This finding of domain differences in epistemological understanding is consistent with the view of Kuhn, Iordanou, et al. (2008), who suggest that there are different challenges in the development of epistemological understanding across domains. The major challenge in the social domain is to overcome the view that human interpretation plays an unmanageable, overpowering role, whereas the major challenge in the science domain is to recognize that human interpretation plays any role at all (Kuhn, Iordanou, et al., 2008). The domain differences in epistemological understanding that we observed also highlight domain differences in evidential standards (Chinn et al., 2011). Students who engaged in a science-focused argument intervention exhibited an appreciation of scientific evidence and they considered it central for belief formation. On the other hand, students who participated in the same intervention but focused on a social topic appeared to consider personal experiences as meeting sufficient evidential standards. These findings have important educational implications, pointing to the challenge of supporting an understanding that evaluation of different views based on criteria is feasible not only in the physical science domain, but also in the social science domain.

In addition to differences across domains, differences were also observed within a domain. The students who participated in an argument-focused intervention on a social topic showed improvements in their epistemological understanding, measured with a scenario-based instrument about a fictitious $5^{\text {th }}$ Livia war; however, when they were asked about their epistemological understanding on homeschooling, their intervention topic, they didn't seem to value evidence as a source of knowledge. These differences might suggest that there are topicspecific differences in epistemological understanding, even within a particular domain (Kuhn, 
Iordanou et al., 2008). These differences might also suggest that although students had developed some evaluativist epistemological understanding, evidenced by the appreciation they developed toward research in the scenario-based instrument, this understanding was not yet complete, as evidenced by their limited appreciation toward evidence in the individual interviews. Further research is required to gain a better understanding of domain-specificity of both epistemological understanding and epistemological development. One limitation of the present study is that it examined participants' epistemological understanding only before and after the intervention. It would have been informative if participants' epistemological understanding were also examined throughout the intervention. Finally, given the complexity of epistemological understanding, future research should examine how engagement in argumentation influences the development of different components of epistemic cognition, such as epistemic values and justification of knowledge (Chinn et al., 2011; Greene, Muis, \& Pieschl, 2010). Nevertheless, the findings of the present study suggest that argumentation is a promising pathway for the development of epistemological understanding. Through argumentation students develop an understanding that knowledge is amenable to critique and evaluation; such an understanding is central to the development of evaluativist epistemological understanding that is fundamental to learning and reasoning. 


\section{References}

Bråten, I., Britt, M. A., Strøms $\varnothing$, H. I., \& Rouet, J. F. (2011). The role of epistemic beliefs in the comprehension of multiple expository texts: Toward an integrated model. Educational Psychologist, 46, 48-70.

Chinn, C. A., Buckland, L. A., \& Samarapungavan, A. (2011). Expanding the dimensions of epistemic cognition: Arguments from philosophy and psychology. Educational Psychologist, 46(3), 141-167.

Greene, J. A., Azevedo, R., Torney-Purta, J. (2008). Modelling epistemic and ontological cognition: Philosophical perspectives and methodological directions. Educational Psychologist, 43, 142-160.

Hofer, B. K. (2004). Epistemological understanding as a metacognitive process: Thinking aloud during online searching. Educational Psychologist, 39, 43-55.

Hofer, B. K., \& Pintrich, P. R. (1997). The development of epistemological theories: Beliefs about knowledge and knowing and their relation to learning. Review of Educational Research, 67, 88-140.

Iordanou, K. (2010). Developing argument skills across scientific and social domains. Journal of Cognition and Development.11(3), 293-327.

Iordanou, K., \& Constantinou, C. P. (2014). Developing pre-service teachers' evidence-based argumentation skills on socio-scientific issues. Learning and Instruction, 34, $42-57$.

Iordanou, K., \& Constantinou, C. P. (2015). Supporting use of evidence in argumentation through practice in argumentation and reflection in the context of SOCRATES learning environment. Science Education, 99 (2), 282-311.

Iordanou, K., Muis, K., \& Kendeou, P. (submitted). Epistemic perspective and online epistemic processing of evidence: Developmental and domain differences.

King, P.M. \& Kitchener, K.S. (1994). Developing reflective judgment: Understanding and promoting intellectual growth and critical thinking in adolescents and adults. San Francisco: Jossey-Bass.

Kuhn, D. (1991). The skills of argument. Cambridge, UK: Cambridge University Press.

Kuhn, D., Cheney, R., \& Weinstock, M. (2000). The development of epistemological understanding. Cognitive Development, 15(3), 309-328. 
Kuhn, D., Goh,W., Iordanou, K., \& Shaenfield, D. (2008). Arguing on the computer: A microgenetic study of developing argument skills in a computer-supported environment. Child Development, 79(1), 233-234.

Kuhn, D., Iordanou, K., Pease, M., \& Wirkala, C. (2008). Beyond control of variables: What needs to develop to achieve skilled scientific thinking? Cognitive Development, 23, 435451.

Kuhn, D., Zillmer, N., Crowell, A., \& Zavala, J. (2013). Developing norms of argumentation: Metacognitive, epistemological, and social dimensions of developing argumentive competence. Cognition and Instruction, 31(4), 456-496.

Leach, J., Driver, R., Millar, R., \& Scott, P. (1997). A study of progression in learning about 'the nature of science': Issues of conceptualization and methodology. International Journal of Science Education, 19, 147-166.

Linn, M., Shear, L., Bell, P., \& Slotta, J. (1999). Organizing principles for science education partnerships: Case studies of students' learning about 'rats in space' and 'deformed frogs'. Educational Technology Research and Development, 47(2), 61-84.

Mason, L., \& Scirica, F. (2006). Prediction of students' argumentation skills about controversial topics by epistemological understanding. Learning and Instruction, 16(5), 492-509.

Mason, L., Ariasi, N., \& Boldrin, A. (2011). Epistemic beliefs in action: Spontaneous reflections about knowledge and knowing during online information searching and their influence on learning. Learning and Instruction, 21, 137-151.

Mason, L., Boldrin, A., \& Ariasi, N. (2010). Epistemic metacognition in context: Evaluating and learning online information. Metacognition and Learning, 4, 67-90.

Mason, L., Gava, M., \& Boldrin, A. (2008). On warm conceptual change: The interplay of text, epistemological beliefs, and topic interest. Journal of Educational Psychology, 100(2), 291309.

Muis, K. R. (2008). Epistemic profiles and self-regulated learning: Examining relations in the context of mathematics problem solving. Contemporary Educational Psychology, 33, 177208.

Muis, K. R., Bendixen, L. D., \& Haerle, F. C. (2006). Domain-generality and domain-specificity in personal epistemology research: Philosophical and empirical reflections in the development of a theoretical framework. Educational Psychology Review, 18(1), 3-54.

Nussbaum, E. M., Sinatra, G. M., \& Poliquin, A. (2008). Role of epistemic beliefs and scientific argumentation in science learning. International Journal of Science Education, 30(15), 1977-1999. 
Perry, W. G. Jr. (1970). Forms of intellectual and ethical development in the college years: A scheme. New York, NY: Holt, Rinehart and Winston.

Schommer, M. (1994). Synthesizing epistemological belief research: Tentative understandings and provocative confusions. Educational Psychology Review, 6, 293-319.

Schommer, M., Crouse, A.,\& Rhodes, N. (1992). Epistemological beliefs and mathematical text comprehension: believing it is simple does not make it so. Journal of Educational Psychology, 84, 435-443.

Strømsø, H. I., \& Bråten, I. (2010). The role of personal epistemology in the self-regulation of internet-based learning. Metacognition and Learning, 5(1), 91-111.

Strøms $\varnothing$, H. I., Bråten, I., \& Britt, M. A. (2011). Do students' beliefs about knowledge and knowing predict their judgement of texts' trustworthiness? Educational Psychology, 31(2), 177-206. 
Table 1. The Livia Problem

North and South Livia are two small countries that existed in the 1800s in Asia. There occurred a series of conflicts between the two countries, termed the Livian Wars. There are two brief accounts of the Fifth Livian War that took place in 1878.

A brief account of the Fifth Livian War by J. Abman, National Historian of North Livia.

On the $19^{\text {th }}$ July 1878 , during a national ceremony in North Livia to honor one of their national leaders, ceremonies were interrupted by a sneak attack from South Livia. Thus began the Fifth Livian wan. Because the North Livians were caught by surprise, they were unprepared at first and the South Livians won a few early battles. Then North Livia began to win. But before the North Livians could reach a final victory, a neighboring large country intervened to stop further bloodshed. Despite their early setbacks, the later sweeping victories of the North Livians showed they would have won had the fighting continued. As a result of this war, South Livians finally recognized anything they gained from North Livians would have to be worked out through peaceful negotiations. So ended the Livian Wars.

A brief account of the Fifth Livian War by N. Ivan, National Historian of South Livia

In the last war, North Livia had beaten South Livia, taken some of its land, and refused to leave. South Livia could no longer accept this situation and spent much money to strengthen its 
military. On $20^{\text {th }}$ July 1878 , the Fifth Livian war began. The war took place with rapid, dramatic victories for South Livia, resulting in great celebration. After these dramatic victories, the South Livians suffered some minor losses. But then a neighboring large country intervened to stop further bloodshed. Despite their later setbacks, South Livia's victory seemed assured because of its position of strength. As a result of this war, South Livians felt a new self-respect. They had felt embarrassed by their previous defeats, but now they had proven they were the equals of the North Livians. Because South Livians had achieved military respect, they were willing to work out differences through peaceful negotiations, thus ending the Livian Wars. 
Table 2. The Frogs problem.

Across North America frogs are being found that have major physical deformities. Some frogs have deformed eyes. Others have misshapen or multiple legs -- or they are missing their legs altogether! The following are two brief accounts of why the frogs are being deformed.

A brief account of why the frogs are being deformed

By G. Agmon

Scientist investigating the frogs

North American frogs have been found with deformed legs. The deformed frogs have cysts in the area from which their legs develop. These cysts are caused by parasites. The parasites enter the tadpole early in its development and burrow into the area from which their legs develop. As the tadpole develops into an adult frog, the cysts caused by the parasites interfere with normal development, and the frog develops with leg deformities such as multiple legs or no legs. In order to test whether the parasites cause the deformities in the frogs, small plastic beads were surgically implanted into tadpoles in the location where cysts were observed in adult frogs - in the area of the body from which legs develop. Many of the frogs that developed from these tadpoles had multiple legs and feet coming out of the area in which the plastic bead was implanted. Parasites in the water are causing these deformities in the frogs. 
A brief account of why the frogs are being deformed

by M. Moyal

Scientist investigating the frogs

In recent years, North American frogs have been found with deformed legs and eyes. Chemicals in the water are causing deformities in the North American frogs. The chemicals in the water come in contact with the tadpoles while they are developing, and this contact causes a reaction that interferes with normal development. As a result, the adult frogs that develop from these tadpoles have deformed body parts.

In order to test whether the suspected chemical was in the water, a sample of water from the area where the frogs live was taken. The water was treated with a substance that is known to cause a reaction with the suspected chemical, and the expected reaction did indeed occur. In order to test whether this chemical can cause the observed deformities, the chemical was applied to normal tadpoles, and the frogs that developed had deformities similar to those observed in the North American frogs. 
Table 3. Levels of epistemological understanding on the Livia and Frog problem

Level

Frog Problem

Absolutist

Certainty empirically possible via direct observation or by appealing to authority.

Certainty only theoretically possible, due to practical limitations.

Certainty not possible due to absence of observers, but theoretically would be if an observer had been present

Multiplist

Certainty not possible due to the subjectivity associated with human phenomena

Evaluativist

Certainty not possible but approachable through

investigation and interpretation of evidence
Livia Problem

If he were in the war he would know.
You can't know what happened. Each historian has his own view.

\section{Pursue more research}

